\title{
Synthesis and Properties of Nitrogen-Doped Graphene as Anode Materials for Lithium-Ion Batteries
}

\author{
Changjing $\mathrm{Fu}^{*}$, Chunlai Song, Lilai Liu, Xuedong Xie, Weiling Zhao
}

School of Materials Science and Engineering, Heilongjiang University of Science and Technology, 2468 Puyuan Road, Harbin 150022, P.R. China

*E-mail: fcj_hit@163.com

doi: $10.20964 / 110391$

Received: 20 January 2016 / Accepted: 25 February 2016 / Published: 1 April 2016

\begin{abstract}
Nitrogen-doped graphene (N-rGO) was successfully synthesized during the reduction of graphene oxide by the modified Hummers' method. In contrast to the reduced graphene oxide (rGO), N-rGO presented superior morphology, structure and composition as the anode of lithium-ion batteries (LIBs) according to the examination of SEM, TEM, XRD, Raman spectrum and XPS. The doping content of nitrogen in N-rGO was about 7.98 at.\%. The electrochemical performances of N-rGO as anodes of LIBs were also evaluated accordingly. Thus-prepared N-rGO showed a higher reversible specific capacity of $332 \mathrm{mAh} \mathrm{g}^{-1}$ during 600 cycles at $500 \mathrm{~mA} \cdot \mathrm{g}^{-1}$. Even at $4 \mathrm{~A} \cdot \mathrm{g}^{-1}$, a reversible capacity of 208 $\mathrm{mAh} \cdot \mathrm{g}^{-1}$ can still be maintained. The improved electrochemical performance of $\mathrm{N}-\mathrm{rGO}$ as anodes of LIBs could be due to the specific characteristics of the unique nanostructures, the covalent interactions between $\mathrm{N}$ and graphene, the good conductivity and high surface areas, which reduce the transfer resistance for $\mathrm{Li}$-ion and electron and provide more extra live regions for $\mathrm{Li}$ storage.
\end{abstract}

Keywords: Lithium-ion batteries, Anode, N-rGO, Synthesis

\section{$\underline{\text { FULL TEXT }}$}

(C) 2016 The Authors. Published by ESG (www.electrochemsci.org). This article is an open access article distributed under the terms and conditions of the Creative Commons Attribution license (http://creativecommons.org/licenses/by/4.0/). 